\title{
Emergence agitation or delirium in children
}

\author{
Yi Zou ${ }^{1}$ Shao-Hua Liu ${ }^{1} \cdot$ Fu-Shan Xue ${ }^{1}$ (]) \\ Received: 23 March 2020 / Accepted: 3 May 2020 / Published online: 14 May 2020 \\ (c) Japanese Society of Anesthesiologists 2020
}

Keywords Emergence delirium $\cdot$ Emergence agitation $\cdot$ Children

\section{To the Editor:}

In recent article of Cho et al. [1], comparing two drugs for prevention of emergence delirium (ED) in children, we noted several issues that needed further clarification. First, ED determined using a four-point agitation scale was best called as emergence agitation, as they do not meet the diagnostic criteria of delirium in the DSM-5 required by 2018 newest recommendations for nomenclature of cognitive change associated with anesthesia and surgery [2]. Second, this only used PAED scale to quantify severity of ED, but not to identify ED. As an ideal and valid rating tool, PAED scale has been widely accepted to identify and quantify ED in children; i.e., a score $\geq 10$ has $64 \%$ sensitivity and $86 \%$ specificity, and a score $>12$ has $100 \%$ sensitivity and $94.5 \%$ specificity for diagnosing ED. Third, postoperative pain score differ significantly between groups, but postoperative analgesic data were not provided and compared. As postoperative pain is a known precipitating factor for ED in children, we were concerned that unbalanced postoperative pain treatments would have biased their findings. Fourth, because of a small sample, this study has no enough power to determine significant differences in the four-point agitation scale, PAED score and incidence of severe ED among various age

Cho EA, et al. Comparison of single minimum dose administration of dexmedetomidine and midazolam for prevention of emergence delirium in children: a randomized controlled trial. J Anesth. 2020; 34:59-65.

This comment refers to the article available online at https://doi. org/10.1007/s00540-019-02705-6.

\footnotetext{
Fu-Shan Xue

xuefushan@aliyun.com

1 Department of Anesthesiology, Beijing Friendship Hospital, Capital Medical University, NO. 95

Yong-An Road, Xi-Cheng District, Beijing 100050,

People's Republic of China
}

children. Fifth, preoperative anxiety levels should be present as median with a range and compared between groups.

Acknowledgement All authors have no financial support and potential conflicts of interest for this work.

\section{Compliance with ethical standards}

Conflict of interest The authors declare that they have no conflict of interest.

\section{References}

1. Cho EA, Cha YB, Shim JG, Ahn JH, Lee SH, Ryu KH. Comparison of single minimum dose administration of dexmedetomidine and midazolam for prevention of emergence delirium in children: a randomized controlled trial. J Anesth. 2020;34:59-655.

2. Evered L, Silbert B, Knopman DS, Scott DA, DeKosky ST, Rasmussen LS, Oh ES, Crosby G, Berger M, Eckenhoff RG, Nomenclature Consensus Working Group. Recommendations for the nomenclature of cognitive change associated with anaesthesia and surgery-2018. Anesthesiology. 2018;129:872-9.

Publisher's Note Springer Nature remains neutral with regard to jurisdictional claims in published maps and institutional affiliations. 